\title{
Killed in action (KIA): an analysis of military personnel who died of their injuries before reaching a definitive medical treatment facility in Afghanistan (2004- 2014)
}

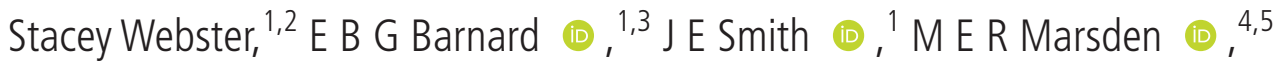 \\ C Wright $^{1}$
}

${ }^{1}$ Academic Department of Military Emergency Medicine, Royal Centre for Defence Medicine (Research and Academia), Birmingham, UK ${ }^{2}$ The 2nd Battalion Parachute Regiment, Colchester, UK ${ }^{3}$ Emergency Department, Cambridge University Hospitals NHS Foundation Trust, Cambridge, UK

${ }^{4}$ Academic Department of Military Surgery and Trauma, Royal Centre for Defence Medicine (Research and Academia), Birmingham, UK ${ }^{5}$ Centre for Trauma Sciences, Blizard Institute, Queen Mary University of London, London, UK

\section{Correspondence to}

Capt Stacey Webster, Academic Department of Military Emergency Medicine, Royal Centre for Defence Medicine (Research and Academia), Birmingham, United Kingdom; stacey.webster@doctors.org.uk

Received 14 April 2020

Revised 7 May 2020

Accepted 8 May 2020

Published Online First

2 June 2020

\section{SLinked}

- http://dx.doi.org/10.1136/ bmjmilitary-2020-001593

Check for updates

(C) Author(s) (or their employer(s)) 2021. No commercial re-use. See rights and permissions. Published by BMJ.

To cite: Webster $S$

Barnard EBG, Smith JE, et al. BMJ Mil Health

2021:167:84-88.

\section{ABSTRACT}

Introduction The majority of combat deaths occur before arrival at a medical treatment facility but no previous studies have comprehensively examined this phase of care.

Methods The UK Joint Theatre Trauma Registry was used to identify all UK military personnel who died in Afghanistan (2004-2014). These data were linked to non-medical tactical and operational records to provide an accurate timeline of events. Cause of death was determined from records taken at postmortem review. The primary objective was to report time between injury and death in those killed in action (KIA); secondary objectives included: reporting mortality at key North Atlantic Treaty Organisation timelines $(0,10,60,120 \mathrm{~min})$, comparison of temporal lethality for different anatomical injuries and analysing trends in the case fatality rate (CFR).

Results 2413 UK personnel were injured in Afghanistan from 2004 to 2014; 448 died, with a CFR of $18.6 \% .390$ (87.1\%) of these died prehospital $(n=348 \mathrm{KIA}, n=42 \mathrm{killed}$ non-enemy action). Complete data were available for $\mathrm{n}=303(87.1 \%)$ KIA: median Injury Severity Score 75.0 (IQR 55.5-75.0). The predominant mechanisms were improvised explosive device $(n=166,54.8 \%)$ and gunshot wound $(n=96,31.7 \%)$.

In the KIA cohort, the median time to death was 0.0 (IQR 0.0-21.8) min; $173(57.1 \%$ ) died immediately (0 min). At 10, 60 and $120 \mathrm{~min}$ post injury, $205(67.7 \%), 277$ (91.4\%) and 300 (99.0\%) casualties were dead, respectively. Whole body primary injury had the fastest mortality. Overall prehospital CFR improved throughout the period while in-hospital CFR remained constant.

Conclusion Over two-thirds of KIA deaths occurred within 10 min of injury. Improvement in the CFR in Afghanistan was predominantly in the prehospital phase.

\section{INTRODUCTION}

Most fatalities from trauma, in civilian and military settings, die before reaching a medical treatment facility (MTF). ${ }^{12}$ Paradoxically, this is the least researched and understood phase of care. It is accepted that the sooner a patient reaches definitive medical care, the better the outcome from severe trauma. ${ }^{3}$ This has been appreciated for several decades of military conflict, and underpins the concept of MTFs being located as far forward as possible to minimise the time to definitive care. In recent conflicts, life-saving interventions such as

\section{Key messages}

Eighty-seven per cent of UK deaths in Afghanistan were prehospital.

- Over half of the killed-in-action deaths were immediate, and two-thirds occurred within 10 min of injury.

- A primary injury to the head had a significantly shorter time to death compared to the abdomen and to the lower extremity.

- Significant improvement in survival can be attributed to a reduction in the prehospital case fatality rate (CFR) without an increase in the in-hospital CFR.

prehospital emergency anaesthesia, blood transfusion and surgical procedures (for example thoracotomy) were pushed forward into the prehospital environment. These interventions, combined with senior decision making, were used to good effect in the recent conflict in Afghanistan. ${ }^{45}$ These advances in prehospital care have also been adopted in civilian practice, and are associated with improved early mortality.

Historically, death due to trauma was thought to follow a tri-modal distribution. ${ }^{7}$ However, more recently this has been questioned, with many challenging the validity of this model in a modern trauma system. ${ }^{8-10}$ Similarly, the 'Golden Hour' is a widely understood concept that describes the first hour following injury as the optimal period to intervene with life-saving intervention, and this has been used to drive improvement in the initial management of trauma patients and indeed the entire trauma pathway. However, the $60 \mathrm{~min}$ of the 'Golden Hour' are not based on robust evidence. It is not known how quickly life-saving intervention is needed in patients with time-critical potentially fatal injuries.

Op HERRICK was the UK's contribution to the conflict in Afghanistan between 2002 and 2014. Survival from a given injury severity improved year on year throughout the course of the conflict but further analysis is necessary to define where these benefits occurred. ${ }^{5}$ It has been suggested that in order to improve future survival rates, we should focus on the died-of-wounds cohort, ${ }^{11}$ but most 
fatalities occurred prehospital and therefore these patients could hold the greatest potential for improving survival.

Research in this area is inherently difficult to conduct, with the majority of existing evidence and data analyses focussing on patients after arrival at a hospital. Previous analyses of casualties who die before arrival at an MTF, or who subsequently die of their wounds, have not included any detail on the time it takes for patients to die from battlefield injuries. ${ }^{111} 12$ This remains a poorly researched area that may provide some evidence to support recommendations and timelines in prehospital emergency care. Eastridge et al identified this as an unexploited blind spot in the epidemiology of battlefield injuries, which is integral to improving future mortality. ${ }^{13}$

The primary aim of this study was to define the time interval between injury and death in UK military personnel who were killed in action (KIA) during Op HERRICK. The secondary aims were to: (a) compare the time to death for the most prevalent primary anatomical injuries; (b) report mortality at key North Atlantic Treaty Organisation (NATO) timelines $(0,10,60$, $120 \mathrm{~min})$; and (c) analyse overall, prehospital and in-hospital mortality rates during Op HERRICK.

\section{METHODS}

The UK Joint Trauma Theatre Registry (JTTR) contains data on all UK service personnel who were injured who either activated a trauma team in a deployed MTF, or who died of their injuries. The JTTR was searched to identify all UK service personnel who died in Afghanistan during Op HERRICK between 2004 and 2014. Cause of death was determined from records made at postmortem examination. If casualties were multiply injured their primary cause of death was used for analysis.

JTTR does not include accurate time of death data for casualties who died before arrival at an MTF. Therefore, the JTTR was cross-referenced with tactical and operational (non-medical) logs to develop a comprehensive database that included accurate timeline data. Time of prehospital death was defined as loss of a central pulse or the start of cardiopulmonary resuscitation. Other key definitions are in Table 1.

Body regions are recorded within JTTR. ${ }^{11}$ For clarity, 'lower extremity' includes pelvis, and 'whole body' is defined as: massive, multiple organ injury to thorax and/or abdomen with loss of one or more limbs and/or decapitation.

\section{Data analysis}

Data were collated in a Microsoft Excel spreadsheet, and analysed in Prism 8 for Mac OS V.8.3.0 (GraphPad Software, San

\begin{tabular}{ll}
\hline Table 1 Key definitions & \\
\hline Abbreviation & Definition \\
\hline KIA & $\begin{array}{l}\text { Injured as a result of enemy action, died before } \\
\text { arrival at hospital } \\
\text { Injured as a result of enemy action, died after } \\
\text { arrival at hospital } \\
\text { Injured as a result of non-enemy action, died } \\
\text { before arrival at hospital }\end{array}$ \\
\hline KNEA & $\begin{array}{l}\text { Injured as a result of non-enemy action, died } \\
\text { after arrival at hospital }\end{array}$ \\
DNEA & $\begin{array}{l}\text { Number of deaths/total number of those } \\
\text { injured; reported as a percentage. }\end{array}$ \\
\hline
\end{tabular}

CFR, case fatality rate; DNEA, died non-enemy action; DOW, died of wounds; KIA, killed in action; KNEA, killed non-enemy action.
Diego, California, USA). Descriptive data are presented as n (\%) and median (IQR).

Comparisons of proportions at fixed time points (for example the proportion of 'whole body' casualties dead at 0 min compared with the proportion of 'head' casualties dead at $0 \mathrm{~min}$ ) were undertaken with a two-tailed Fisher's exact test. Significance was predefined as $\mathrm{p}<0.05$, and corrected for multiple comparisons using the Bonferroni method $(0.05 / \mathrm{K}$, where $\mathrm{K}$ is defined as the total number of comparisons).

The time to death (survival curve) between different primary injuries was analysed with a two-tailed Gehan-Breslow-Wilcoxon test. This test gives more weight to earlier deaths than a Logrank test ${ }^{14}$ which is important when comparing rates of mortality after injury. Overall significance (testing the hypothesis that all survival curves are identical) was predefined as $p<0.05$. For between-group comparisons, the significance threshold was corrected using the Bonferroni method.

In order to analyse differences in case fatality rate (CFR) throughout the study period, the proportion of deaths were compared between the first and last year of data in (a) the overall CFR, (b) the prehospital CFR and (c) in the in-hospital CFR with a two-tailed Fisher's exact test. To provide direction and an estimate of magnitude and precision, a Baptista-Pike OR was reported alongside the Fisher's $\mathrm{p}$ value, and has been reported as OR $(95 \% \mathrm{CI})$. A $\chi^{2}$ test for trend was then applied to each group, and a $\mathrm{p}$ value $<0.05$ indicates a significant linear trend over time.

\section{RESULTS}

A total of 2413 UK service personnel were injured during Op HERRICK (2004-2014). Army personnel accounted for the largest number of injured $n=2051(85.0 \%)$; followed by Royal Marines $n=261$ (10.8\%); Royal Air Force $n=89$ (3.7\%); and Royal Navy $\mathrm{n}=12(0.5 \%)$. During this period, 448 personnel died; an overall CFR of $18.6 \%$.

Of the 448 deaths, $87.1 \%$ died prehospital (KIA and killed non-enemy action (KNEA)), (Figure 1). The predominant mechanisms of injury in the KNEA group were aircraft incidents $(n=20)$ and motor vehicle collisions $(n=10)$ - these deaths are not described further. Complete timeline data were available for $n=303(87.1 \%)$ of those KIA, which forms the definitive cohort for further analyses (Figure 1).

\section{KIA cohort}

These 303 personnel had a median Injury Severity Score of 75.0 (55.5-75.0). The predominant mechanism of injury was improvised explosive device (IED) $\mathrm{n}=166$ (54.8\%), followed by gunshot wound $n=96$ (31.7\%); explosive (non-IED, for example mine/grenade) $\mathrm{n}=40(13.2 \%)$; and a single death from an aircraft incident.

The most prevalent primary injury was head, followed by thorax, and lower extremity. 'Whole body' injury was reported in $\mathrm{n}=21$ (one was injured in an aircraft incident and the remainder were injured by IED) (Table 2).

The median time between injury and death was $0.0(0.0$ 21.8 min. At 10, 60 and 120 min post injury, $\mathrm{n}=205(67.7 \%)$, $\mathrm{n}=277(91.4 \%)$ and $\mathrm{n}=300(99.0 \%)$ casualties were dead, respectively (Figure 2). Three KIA deaths occurred $>120 \mathrm{~min}$ post injury: at 133, 144 and $221 \mathrm{~min}$ (Table 2).

\section{Immediate deaths}

In $173(57.1 \%)$ cases, death was immediate (recorded as $0 \mathrm{~min}$ ); head was the most prevalent injury (Table 2). The immediate mortality of the top six anatomical injury regions listed in Table 2 


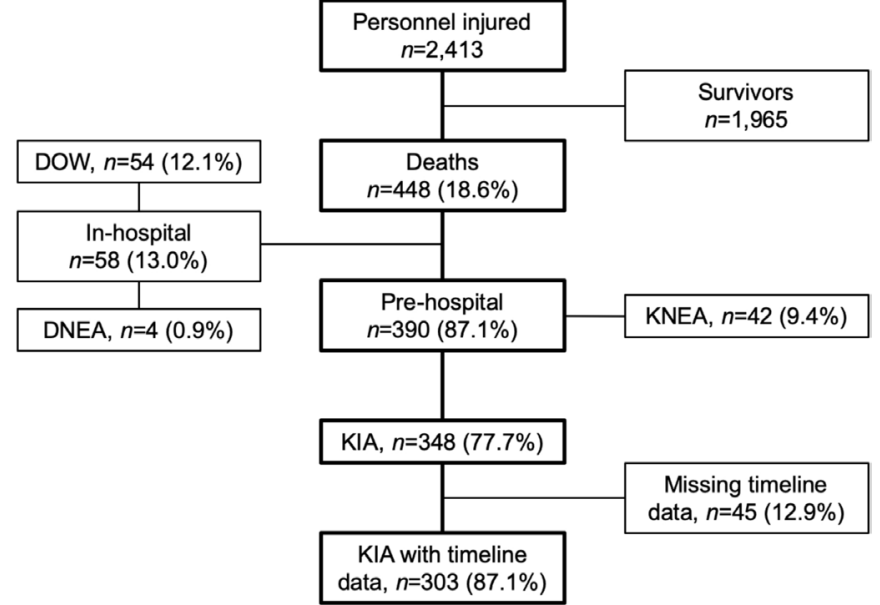

Figure 1 A CONSORT diagram of UK service personnel injured in Afghanistan (2004-2014) describing the definitive cohort (KIA with complete timeline data). CONSORT, Consolidated Standards of Reporting Trials; DOW, died of wounds; DNEA, died non-enemy action; KIA, killed in action; KNEA, killed non-enemy action.

were compared-a total of 15 comparisons, resulting in a significance threshold of $\mathrm{p}<0.0034$. The highest immediate mortality was observed in the 'whole body' group (95.7\%), significantly higher than neck $(p=0.0029)$, thorax $\left(p=0.84 \times 10^{-4}\right)$, abdomen $\left(\mathrm{p}=0.48 \times 10^{-5}\right)$ and lower extremity $\left(\mathrm{p}=0.12 \times 10^{-5}\right)$ groups. The second highest immediate mortality was observed in the head group (66.9\%), significantly higher than abdomen $(p=0.0019)$ and lower extremity $(\mathrm{p}=0.0004)$ groups. There were no significant differences in the proportion of immediate death between the other anatomical regions examined (Figure 3).

\section{Analysis of time to death for different primary injuries}

Survival curve analysis was undertaken for the top six anatomical injury regions listed in Table 2 and illustrated in Figure 3; the corrected significance threshold was $p<0.0034$. The survival curves were significantly different, $p=0.91 \times 10^{-5}$. In individual comparisons, there were statistical differences in survival between: (1) 'whole body' and thorax $(\mathrm{p}=0.0004)$, abdomen $\left(\mathrm{p}=0.12 \times 10^{-4}\right)$ and lower extremity $\left(\mathrm{p}=0.23 \times 10^{-5}\right)$ groups; and (2) between head and abdomen $(\mathrm{p}=0.0020)$, and lower extremity $\left(p=0.46 \times 10^{-4}\right)$ groups. There were no other significant differences in survival between the groups examined (Figure 3).

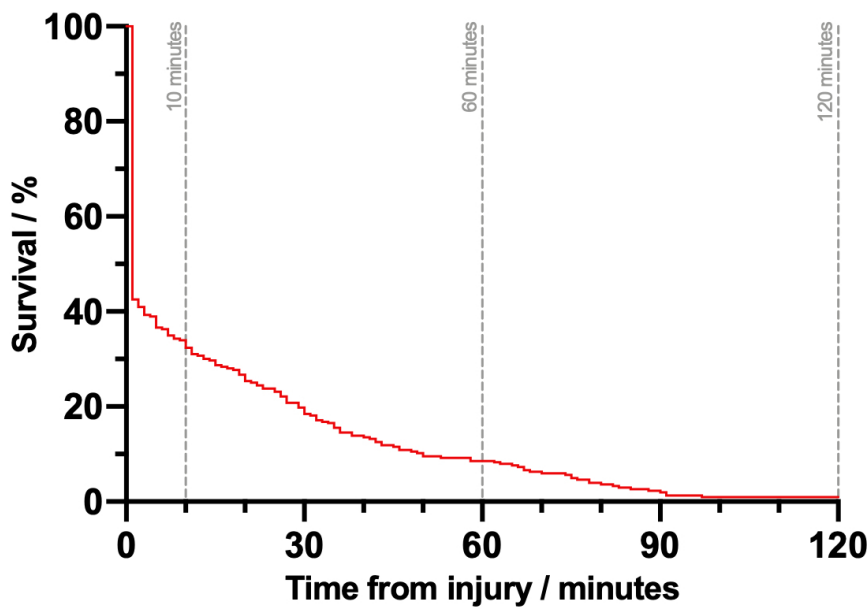

Figure 2 Survival curve for $n=303$ UK service personnel who were killed in action in Afghanistan (2004-2014).

\section{Changes in CFR over time}

The CFR during the study period was $18.6 \%$ (including all classifications of death). There were only $n=4$ total casualties in 2004 and 2005 and $n=35$ in 2014, therefore data from 2006 to 2013 have been used for this analysis.

There was a significant reduction in overall CFR between 2006 and 2013, from 42.9\% to 6.2\%: OR 11.3 (95\%CI 5.2 to 25.4$), \mathrm{p}=0.16 \times 10^{-10}$. These data demonstrated a downward trend during the study period, $p=0.16 \times 10^{-8}$ (Figure 4).

During the same time, there was a significant reduction in prehospital CFR, from $41.8 \%$ to $4.8 \%$ : OR 14.2 (95\%CI 5.9 to 35.5$), p=0.26 \times 10^{-11}$, and these data demonstrated a downward trend throughout the period, $\mathrm{p}=0.35 \times 10^{-9}$. There was no apparent change in in-hospital CFR between 2006 (1.1\%) and 2013 (1.4\%): OR 0.77 (95\%CI 0.09 to 11.3$), p=1.0$; there was no linear trend observed in the in-hospital CFR, $p=0.48$ (Figure 4).

\section{DISCUSSION}

This study has shown that over half $(57.1 \%)$ of UK prehospital deaths in Afghanistan 2004-2014 were immediate. A further $10.6 \%$ died within 10 min of injury; therefore, over two-thirds died within the first $10 \mathrm{~min}$, without any realistic opportunity for advanced medical intervention. In addition, for the first time, we have demonstrated that different body region injuries show different temporal lethality. Whole body and head injuries

Table 2 The time interval between injury and death in UK casualties with complete timeline data who were killed in action during Op HERRICK

\begin{tabular}{|c|c|c|c|c|c|c|}
\hline \multirow[b]{2}{*}{ Region } & \multicolumn{5}{|c|}{ Time interval between injury and death/min ( $\mathrm{n}(\%))$} & \multirow{2}{*}{$\begin{array}{l}\text { Overall } \\
\mathrm{n}(\%)\end{array}$} \\
\hline & Immediate & $1-10$ & $11-60$ & $61-120$ & $>120$ & \\
\hline Head & $83(48.0 \%)$ & $13(40.6 \%)$ & $23(31.9 \%)$ & $4(17.4 \%)$ & $1(33.3 \%)$ & $124(40.9 \%)$ \\
\hline Thorax & $29(16.8 \%)$ & $6(18.8 \%)$ & $13(18.1 \%)$ & $9(39.1 \%)$ & 0 & $57(18.8 \%)$ \\
\hline Lower extremity & $11(6.4 \%)$ & $1(3.1 \%)$ & $16(22.2 \%)$ & $6(26.1 \%)$ & 0 & $34(11.2 \%)$ \\
\hline Neck & $16(9.2 \%)$ & $6(18.8 \%)$ & $5(6.9 \%)$ & 0 & 0 & $27(8.9 \%)$ \\
\hline Abdomen & $9(5.2 \%)$ & $5(15.6 \%)$ & $11(15.3 \%)$ & $1(4.3 \%)$ & $1(33.3 \%)$ & $27(8.9 \%)$ \\
\hline Whole body & $22(12.7 \%)$ & $1(3.1 \%)$ & 0 & 0 & 0 & $23(7.6 \%)$ \\
\hline Spine & $3(1.7 \%)$ & 0 & $3(4.2 \%)$ & $2(8.7 \%)$ & $1(33.3 \%)$ & $9(3.0 \%)$ \\
\hline Face & 0 & 0 & 0 & 1 & 0 & $1(0.3 \%)$ \\
\hline Upper extremity & 0 & 0 & 1 & 0 & 0 & $1(0.3 \%)$ \\
\hline Total (n (\%)) & $173(57.1 \%)$ & 32 (10.6\%) & $72(23.8 \%)$ & $23(7.6 \%)$ & $3(1.0 \%)$ & 303 \\
\hline
\end{tabular}




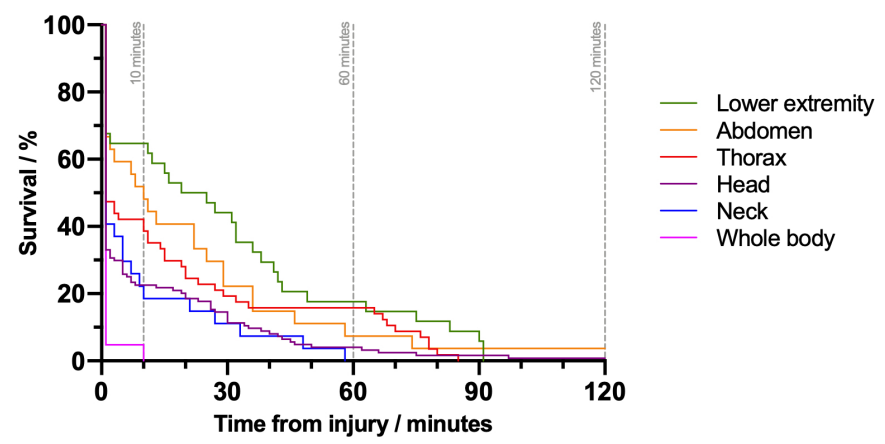

Figure 3 Survival curve for $n=290$ UK service personnel who were killed in action in Afghanistan (2004-2014) by primary anatomical injury recorded in the UK Joint Theatre Trauma Registry.

result in significantly faster death than other anatomical regions. Although lower limb injury was a less common cause of death, when it is the primary injury it results in slower death that may be more amenable to medical intervention. Using novel timeline data, we have demonstrated that improvements in overall trauma survival during Op HERRICK were associated with a reduction in prehospital mortality with no apparent effect on mortality in hospital.

The findings of this study are consistent with existing evidence that the majority of deaths following battlefield trauma occur before arrival at hospital. ${ }^{1}$ However, this also provides granular detail with regard to the timing of death in the early phase of injury. Timelines are of particular doctrinal importance to the military, whose pathways of care for injured personnel on deployed operations dictate how far away from medical support units conduct offensive operations. A balance must be struck between constraining operational missions and providing optimal care to ensure survival of injured patients. Current NATO policy involves a 10-1-2 medical element (all casualties should receive battlefield first aid within $10 \mathrm{~min}$, advanced first aid within 1 hour and surgery within 2 hours). As more than twothirds of deaths occur within the first $10 \mathrm{~min}$ following injury, immediate access to simple but potentially life-saving intervention is an important element of the chain of survival. Most modern militaries recognise that immediate first aid is key to reducing overall mortality and have responded by equipping and

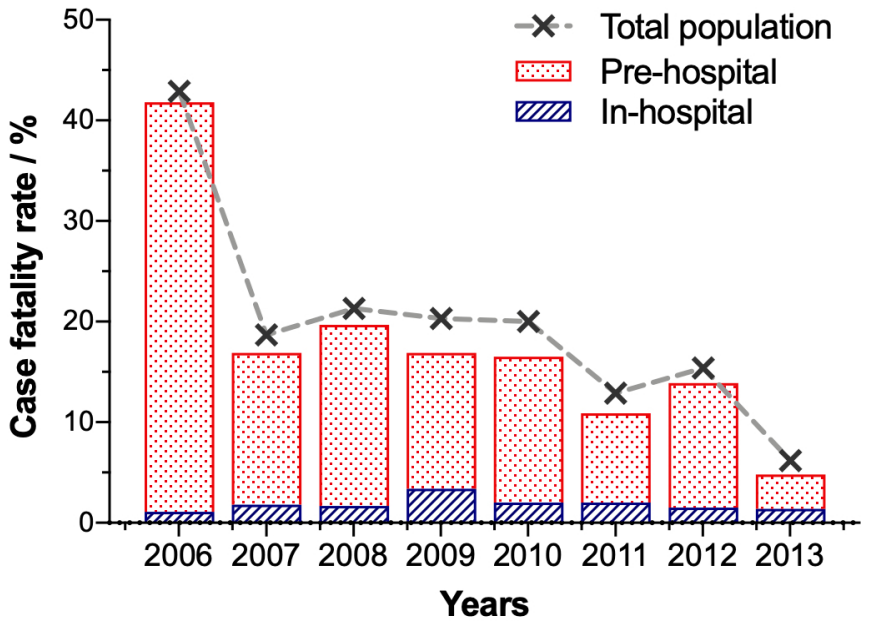

Figure 4 Case fatality rate of UK service personnel injured in Afghanistan (2006-2013) by year. Plotted as total population, prehospital deaths, and in-hospital deaths (data are superimposed). training every soldier in basic techniques such as control of catastrophic haemorrhage, so that the treatment of every casualty can begin as soon as possible after injury, and the data from this study support this.

Previous studies have demonstrated that most preventable trauma deaths occur in the prehospital phase and have suggested that this is where the greatest opportunity for improving survival in the most severely injured patients lies. ${ }^{13}$ This study also supports this concept, as $87 \%$ of patients who die from battlefield trauma do so before reaching an MTF. Military prehospital care covers a broad spectrum of possible interventions that begin at the moment of injury, from self-aid to care under fire, buddy aid, care provided by a combat medic all the way up to Level 8 (consultant-delivered) advanced prehospital care. This entire chain of medical care and interventions has been integral to improving survival during this conflict.

The prehospital CFR reduced during the study period but the in-hospital CFR remained constant; at first glance this may suggest that no improvement in hospital care was made during the period, but as the prehospital CFR reduced, more severely injured patients were delivered to the hospital, and therefore the fact that there was no discernible change actually suggests that over time more severely injured patients had the same chance of survival, as eloquently demonstrated previously, ${ }^{5}$ suggesting improvements throughout the chain of medical care.

One finding of note was that the CFR has remained similar for over 100 years. ${ }^{15-17}$ This suggests that the lethality of war has matched the pace of medical advances. Death from haemorrhage is still the most significant cause of preventable death, not only on the battlefield but also in civilian trauma. Improving our understanding of how and when these deaths occur shows that the prehospital phase is where the lives of future soldiers will be saved. Evidence suggests that early haemorrhage control, administration of tranexamic acid (TXA) and far forward blood transfusion improve mortality. ${ }^{318-20}$ Future innovations such as the administration of intramuscular TXA through an autoinjector may continue to improve outcomes. Resuscitative endovascular balloon occlusion of the aorta (REBOA) can be used to control haemorrhage and one recent study concluded that one in five severely injured casualties were potentially suitable for REBOA, ${ }^{21}$ but our study suggests that this intervention may not be feasible within the window of opportunity for the majority of patients.

While this data analysis reflects a military population, many of the lessons learnt from the conflict in Afghanistan have been successfully implemented in civilian trauma care. Adoption of an end-to-end trauma system in the UK NHS has resulted in significantly improved mortality. ${ }^{22}$ We live in an unstable world with increasing numbers of battlefield-type injuries being treated in UK emergency departments, whether that be from terrorist incidents, ${ }^{23}$ or due to increasing violence on the streets from knife and gun crime, ${ }^{24}$ and so lessons from this study might be applicable to civilian emergency departments. ${ }^{2}$ It has also been recognised that in terrorist attacks there is a therapeutic vacuum where casualties may die in the hot zone before sufficient medical care can be given. ${ }^{25}$ Therefore, lessons from the battlefield are increasingly applicable to major incident planning and those involved in the trauma care pathway.

This study has several limitations that are inherent to retrospective database review methodology, which relies on the accuracy of data within the JTTR. Accurate prehospital data are notoriously difficult to collect and indeed most studies to date have excluded the prehospital phase of care. The cause 
of death was difficult to confirm in a number of patients due to the complexity of injury, and there was a reliance on postmortem data. The time to death data are estimated from several different sources, and therefore come with a margin of error. There was incomplete data capture and there were some cases for whom accurate timings were not available. Many patients were very severely injured and commonly multiple body regions were injured. However, having access to other military data sources has enabled the collation of a unique, highly detailed database, which has given us the opportunity to analyse with as much certainty as possible what happens in the early stages to critically injured trauma patients during conflict.

\section{CONCLUSION}

This study has demonstrated for the first time the mortality timelines of those military personnel killed in action, and has defined the temporal lethality of different injury patterns. It has shown that over two-thirds of KIA deaths occurred within 10 min of injury, without any obvious opportunity to improve survival. Whole body and head primary injury have a significantly faster mortality than thorax, abdomen and lower extremity injury. The opportunity to further improve combat survival is likely to lie in the prehospital phase of care and may involve developments in haemorrhage control. Improvement in CFR in Afghanistan was predominantly in the prehospital phase. The 'Golden Hour' should not be considered a specific time period, but rather a critical phase of care following injury in which life-saving interventions make a difference to survival.

Correction notice This article has been corrected since it appeared Online First. Corresponding author and address details have been added.

Twitter E B G Barnard @edbarn, J E Smith @DefProfEM, M E R Marsden @ maxmarsden83 and C Wright @DCAPHEC

Acknowledgements The Clinical Information Exploitation Team at the Royal Centre for Defence Medicine and Defence Statistics Health are thanked for collecting, collating and identifying the appropriate data for this paper. Particular thanks also to Ruth McGuire and Alan Hepper, both from Dstl, who provided the operational data.

Contributors SW and CW initiated the idea, collected the data, analysed the results, wrote and reviewed the paper. EBGB analysed the results, wrote and reviewed the paper. MERM and JES wrote and reviewed the paper.

Funding The authors have not declared a specific grant for this research from any funding agency in the public, commercial or not-for-profit sectors.

Competing interests None declared.

Patient consent for publication Not required.

Ethics approval Anonymised data were supplied from the JTTR, and according to institutional agreement, ethical approval was not required. Permission to use postmortem data was obtained from the Oxfordshire Senior Coroner. The project was registered with the Academic Department of Military Emergency Medicine at the Royal Centre for Defence Medicine, Birmingham, UK—reference number: ADMEM2020/0001

Provenance and peer review Not commissioned; externally peer reviewed.

Data availability statement Data are available upon reasonable request. Data has been collated from JTTR and Dstl databases.

\section{ORCID iDs}

E B G Barnard http://orcid.org/0000-0002-5187-1952

J E Smith http://orcid.org/0000-0002-6143-0421

M E R Marsden http://orcid.org/0000-0002-7147-6861

\section{REFERENCES}

1 Eastridge BJ, Mabry RL, Seguin P, et al. Death on the battlefield (2001-2011): implications for the future of combat casualty care. J Trauma Acute Care Surg 2012;73:\$431-7.

2 Webster S, Lawton G, Barnard EBG. Violent death in London: in the news, but not in the database. Emerg Med J 2020. doi:10.1136/emermed-2020-209468. [Epub ahead of print: 17 Apr 2020].

3 Holcomb JB. Transport time and Preoperating room hemostatic interventions are important: improving outcomes after severe truncal injury. Crit Care Med 2018:46:447-53.

4 Morrison JJ, Oh J, DuBose JJ, et al. En-route care capability from point of injury impacts mortality after severe wartime injury. Ann Surg 2013;257:330-4.

5 Penn-Barwell JG, Roberts SAG, Midwinter MJ, et al. Improved survival in UK combat casualties from Iraq and Afghanistan: 2003-2012. J Trauma Acute Care Surg 2015;78:1014-20.

6 Brohi K, Gruen RL, Holcomb JB. Why are bleeding trauma patients still dying? Intensive Care Med 2019:45:709-11.

7 Trunkey DD. Trauma. accidental and intentional injuries account for more years of life lost in the U.S. than cancer and heart disease. among the prescribed remedies are improved preventive efforts, speedier surgery and further research. Sci Am 1983;249:28-35.

8 Lerner EB, Moscati RM. The golden hour: scientific fact or medical "urban legend"? Acad Emerg Med 2001;8:758-60.

9 Rogers FB, Rittenhouse KJ, Gross BW. The golden hour in trauma: dogma or medical folklore? Injury 2015;46:525-7.

10 Bardes JM, Inaba K, Schellenberg M, et al. The contemporary timing of trauma deaths. J Trauma Acute Care Surg 2018;84:893-9.

11 Keene DD, Penn-Barwell JG, Wood PR, et al. Died of wounds: a mortality review. J $R$ Army Med Corps 2016;162:355-60.

12 Eastridge BJ, Hardin M, Cantrell J, et al. Died of wounds on the battlefield: causation and implications for improving combat casualty care. J Trauma 2011;71:S4-8.

13 Eastridge BJ, Mabry RL, Blackbourne LH, et al. We don't know what we don't know: prehospital data in combat casualty care. US Army Med Dep J 2011:11-14.

14 Breslow N. Covariance analysis of censored survival data. Biometrics 1974;30:89-99.

15 Gawande A. Casualties of war-military care for the wounded from Iraq and Afghanistan. N Engl J Med 2004;351:2471-5.

16 Carey ME. Learning from traditional combat mortality and morbidity data used in the evaluation of combat medical care. Mil Med 1987;152:6-13.

17 La Revue d'Infanterie.

18 Smith ER, Shapiro G, Sarani B. Fatal wounding pattern and causes of potentially preventable death following the pulse night Club shooting event. Prehosp Emerg Care 2018;22:662-8.

19 Roberts I, Perel P, Prieto-Merino D, et al. Effect of tranexamic acid on mortality in patients with traumatic bleeding: prespecified analysis of data from randomised controlled trial. BMJ 2012:345:e5839.

20 CRASH-2 collaborators, Roberts I, Shakur $\mathrm{H}$, et al. The importance of early treatment with tranexamic acid in bleeding trauma patients: an exploratory analysis of the CRASH-2 randomised controlled trial. Lancet 2011:377:1096-101, 1101.e1-2.

21 Morrison JJ, Ross JD, Rasmussen TE, et al. Resuscitative endovascular balloon occlusion of the aorta: a gap analysis of severely injured UK combat casualties. Shock 2014;41:388-93.

22 Moran CG, Lecky F, Bouamra O, et al. Changing the System - Major Trauma Patients and Their Outcomes in the NHS (England) 2008-17. EClinicalMedicine 2018;23:13-21.

23 Rozenfeld M, Givon A, Shenhar G, et al. A new paradigm of injuries from terrorist explosions as a function of explosion setting type. Ann Surg 2016;263:1228-34.

24 Norton J, Whittaker G, Kennedy DS, et al. Shooting up? analysis of 182 gunshot injuries presenting to a London major trauma centre over a seven-year period. Ann $R$ Coll Surg Eng/ 2018;100:464-74.

25 Park CL, Langlois M, Smith ER, et al. How to stop the dying, as well as the killing, in a terrorist attack. BMJ 2020:368:m298. 